\title{
Let there be Guidance!!!
}

\author{
Atul P Kulkarni \\ Indian Journal of Critical Care Medicine (2020): 10.5005/jp-journals-10071-G23181
}

Surely there is a time to submit to guidance and a time to take one's own way at all hazards.

-Thomas H. Huxley

Sackett and colleagues defined Evidence Based Medicine (EBM) as a conscientious, explicit, and judicious use of current best evidence in making decisions about the care of individual patients. ${ }^{1}$ Essentially, therefore, EBM is meant to help clinicians offer the best possible care to their patients. Since the individual clinicians are not in a position to sift through the voluminous literature, interpret, and correctly apply the evidence to each patient, this is done by a group of experts appointed by the professional bodies or societies from amongst their members. This amalgamated evidence for a particular illness is then termed as Position Statement or Guidelines of that society and disseminated to their members. Thus, EBM is about resolving clinical dilemmas and treating patients. ${ }^{2}$

Adherence to guidelines improves patient outcomes and increases the cost-effectiveness. ${ }^{3}$ Despite this evidence of improved outcomes, and an inherent appeal for the busy clinicians to adopt these guidelines in the routine practice; there are many reasons the guidelines are not adhered to. These include an aversion to using readymade or precooked medicine, a lack of perceived need, absence of familiarity with, and also inaccessibility to the guidelines, an attitude of superiority ("I know better"), and a doubt about the motives of the developers of guidelines. ${ }^{4,5}$ Zhao and Hu discuss other barriers, which may be difficult to overcome, in developing countries or those countries with variable health infrastructure. ${ }^{6}$ According to them, the adherence to guidelines then becomes dependent on the local factors. The lack of medical resources, such as advanced laboratory investigations and treatments (such as troponin $\mathrm{I}$, and $\mathrm{PCl}$ or thrombolysis facilities in a patient with myocardial infarction) in developing countries might prevent the clinician adherence in spite of knowing what the guidelines suggest. $^{6}$

A physician is more likely to follow guidelines if they respect the source, the guidelines are simple to understand and easy to implement and deemed useful. ${ }^{4,7}$

To quote Masic and colleagues 'External clinical evidence can inform, but can never replace, individual clinical expertise, and it is this expertise that decides whether the external evidence applies to the individual patient at all and, if so, how it should be integrated into a clinical decision. ${ }^{8}$ Some clinicians will then refrain from applying the guidelines to their patients quoting this. However, this development of expertise is a life-long learning process, and not to be undertaken lightly. A busy intensivist is likely to benefit in most
Corresponding Author: Atul P Kulkarni, Department of Critical Care Medicine, Department of Anaesthesiology, Critical Care and Pain, Tata Memorial Center, Homi Bhabha National Institute, Parel, Mumbai, Maharashtra, India, e-mail: kaivalyaak@yahoo.co.in

How to cite this article: Kulkarni AP. Let there be Guidance!!!. Indian J Crit Care Med 2020;24(Suppl 1):S1.

Source of support: Nil

Conflict of interest: None

circumstances by following guidelines developed by professional societies like the Indian Society of Critical Care Medicine.

We begin this journey by publishing the first supplement of the year 2020, of the Indian Journal of Critical Care Medicine, with an omnibus of 4 guidelines and position statements formulated by expert groups of the august members of the ISCCM. This is accompanied by a brilliant piece of commentary, on suggestions as to how a member should approach guidelines and position statement, and how a group should go about developing guidelines. I hope our members find this supplement useful, and with more such supplements annually in the offing, wish you a happy reading and good patient outcomes.

\section{References}

1. Sackett DL, Rosenberg WM, Gray JA, Haynes RB, Richardson WS. Evidence- based medicine: what it is and what it isn't. BMJ 1996;312:7172.

2. Haynes RB, Sackett RB, Gray JMA, Cook DC, Guyatt GH. Transferring evidence from research into practice, 1: The role of clinical care research evidence in clinical decisions. ACP J Club 1996;125: A14-A15.

3. Perrier L, Buja A, Mastrangelo G, Vecchiato A, Sandonà $P$, Ducimetière $F$, et al. Clinicians' adherence versus non adherence to practice guidelines in the management of patients with sarcoma: a costeffectiveness assessment in two European regions. BMC Health Serv Res. 2012;12:82.

4. Grol R, Dalhuijsen J, Thomas S, Veld C, Rutten G, Mokkink H. Attributes of clinical guidelines that influence use of guidelines in general practice: observational study. Br Med J 1998;317:858-861.

5. Cabana MD, Rand CS, Powe NR, Wu AW, Wilson MH, Abboud PA, et al. Why don't physicians follow clinical practice guidelines? a framework for improvement [review]. JAMA 1999;282:1458-1465.

6. Zhao D, Hu D. Barriers to translating EU and US CVD guidelines into practice in China. Nat Rev Cardiol. 2012;9:425-429.

7. Cook D, Giacomini M. The trials and tribulations of clinical practice guidelines. JAMA 1999;281:1950-1951

8. Masic I, Miokovic M, Muhamedagic B. Evidence based medicine — new approaches and challenges. Acta Inform Med. 2008;16(4):219-225.

\footnotetext{
(c) The Author(s). 2020 Open Access This article is distributed under the terms of the Creative Commons Attribution 4.0 International License (https://creativecommons. org/licenses/by-nc/4.0/), which permits unrestricted use, distribution, and non-commercial reproduction in any medium, provided you give appropriate credit to the original author(s) and the source, provide a link to the Creative Commons license, and indicate if changes were made. The Creative Commons Public Domain Dedication waiver (http://creativecommons.org/publicdomain/zero/1.0/) applies to the data made available in this article, unless otherwise stated.
} 